\title{
Covalent Inhibition of SARS-CoV-2 RBD-ACE2 Interaction by Aptamers with Multiple Sulfur(VI) Fluoride Exchange Modifications
}

\author{
Zichen Qin, Yiying Zhu and Yu Xiang*
}

Department of Chemistry, Key Laboratory of Bioorganic Phosphorus Chemistry and Chemical Biology (Ministry of Education), Beijing Key Laboratory for Microanalytical Methods and Instrumentation, Tsinghua University, Beijing 100084, China.*Email: xiang-yu@tsinghua.edu.cn

\begin{abstract}
The SARS-CoV-2 spike protein uses its receptor-binding domain (RBD) to interact with the angiotensin-converting enzyme 2 (ACE2) receptor on host cells, establishing the first step of SARSCoV-2 infection. Inhibitors of RBD-ACE2 interaction, therefore, have shown great promise in preventing SARS-CoV-2 infection. Currently known RBD-ACE2 inhibitors are all based on reversible binding and must compete with ACE2 or RBD at the equilibrium. On the other hand, covalent inhibitors, such as those based on sulfur(VI) fluoride exchange (SuFEx) chemistry, can form irreversible chemical bonds with target proteins and offer advantages including higher potency and longer duration of inhibition. Here, we report covalent aptamer inhibitors that can block RBD-ACE2 by forming covalent bonds with RBD. These covalent aptamer inhibitors were developed by equipping known RBD aptamers with multiple SuFEx (mSuFEx) modifications. The mSuFEx-aptamer 6C3-7SF underwent strong covalent bonding with RBD and some of its variants at fast rates $\left(\mathrm{t}_{1 / 2}=20 \sim 29 \mathrm{~min}^{-1}\right)$ and induced more efficient RBD-ACE2 inhibition $\left(\mathrm{IC}_{50}=26 \sim 37 \mathrm{nM}\right)$ than the original aptamer $\left(\mathrm{IC}_{50}>\right.$ $200 \mathrm{nM}$ ) according to an in vitro enzyme-linked immunosorbent assay (ELISA). The covalent bond formation was highly selective to RBD over human serum albumin (HSA) and ACE2, and could occur efficiently in diluted human serum. Peptide fragmentation analyses of the RBD-6C3-7SF adducts revealed multiple sites of covalent bonding on RBD, including K378, R408, Y422, Y424, Y453, and
\end{abstract}


K458. The surprising R408 suggests that context-specific non-N-terminal arginine could be a new type of targetable residue by SuFEx-based covalent inhibitors, which were never reported as reactive with any non-N-terminal arginine in target proteins. In addition, RBD R408 is responsible for binding with ACE2 N90 glycan, and this arginine is conserved in SARS-CoV-2 variants of concern or interest, suggesting that R408 could be the potential site of interest for developing SuFEx-based covalent inhibitors against threatening SARS-CoV-2 variants. Although the compatibility of mSuFEx-based covalent aptamers in cellular and in vivo systems should be further investigated, our study demonstrated the promise of mSuFEx chemistry in constructing potent covalent aptamers to inhibit important protein-protein interactions (PPIs).

\section{Introduction}

The COVID-19 pandemic caused by SARS-CoV-2 has brought severe damages to public health and the global economy. SARS-CoV-2 infection is initiated by the recognition between the SARSCoV-2 spike protein receptor-binding domain (RBD) and the host cell receptor angiotensin-converting enzyme 2 (ACE2). $\stackrel{1-2}{~}$ For this reason, many promising inhibitors target the RBD-ACE2 protein-protein interaction (PPI) for prevention of SARS-CoV-2 infection, including neutralizing antibodies, $\stackrel{3-4}{=}$ small molecules, $\frac{5-6}{-}$ peptides $\frac{7-8}{}$ and DNA aptamers. $\frac{9-10}{}$ All the currently known RBD-ACE2 inhibitors act through non-covalent binding with RBD or ACE2 to block SARS-CoV-2 entry into host cells. Due to the strong RBD-ACE2 interaction, $\frac{1-2}{-2}$ these reversible inhibitors must be competitive in the binding equilibrium. On the other hand, covalent inhibitors, whose mechanism involves irreversible chemical bond formation between the inhibitors and target proteins after binding, offer advantages including higher potency and longer duration of inhibition over their non-covalent counterparts. $\frac{11-14}{}$ The fight against SARS-CoV-2 via targeting RBD-ACE2 can significantly benefit from introducing the covalent inhibition mechanism into our arsenal. However, no covalent RBD-ACE2 inhibitor has been reported.

In recent years, substantial success has been achieved in developing small molecule covalent drugs as enzyme inhibitors,,$\frac{15-16}{}$ including those directing towards the active sites of kinases and proteases $\frac{17-}{}$ $\underline{19}$ through cysteine- $-\underline{20}$ and lysine-targeting $\underline{21}$ warheads. However, to target PPIs of interest, small molecules are generally inefficient in binding shallow protein surfaces or competing with PPI spanning 
a large binding interface at the thousand square angstrom level. Thus, it is extremely challenging to

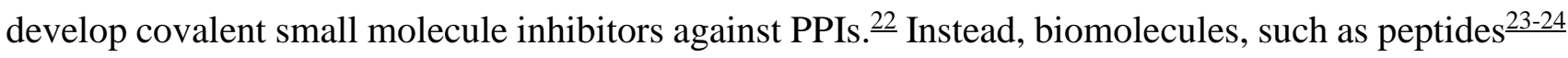
and proteins $\frac{25-26}{}$ are more suitable candidates to inhibit PPIs covalently. In addition, to ensure both selectivity and efficiency in covalent bonding at or near the PPI interface by inhibitors, a latent warhead is needed to stay weakly nucleophilic until reacting with specific amino acid residues under certain circumstances. Warheads based on sulfur(VI) fluoride exchange (SuFEx) chemistry, $\frac{27-30}{}$ such as sulfonyl fluoride and fluorosulfate that were reported to target context-specific lysine, tyrosine, serine, threonine, histidine, and cysteine, meet the criteria very well.

Although proteins,,$\frac{3-4}{}$ peptides,,$\frac{7-8}{-}$ and DNA aptamers $\stackrel{9-10}{=}$ that can bind SARS-CoV-2 RBD have been described, the work of constructing covalent inhibitors of RBD-ACE2 based on these biomolecules is nontrivial. No free cysteine is available in RBD at or near the RBD-ACE2 interface, so that the widely used cysteine-specific warheads are not practical..$^{31}$ DNA aptamers, $\stackrel{32-33}{a}$ class of functional biomolecules obtained through systematic evolution of ligands by exponential enrichment (SELEX), can be chemically synthesized with SuFEx chemistry and are inert to SuFEx warheads. $\underline{\underline{34-35}}$ Taking advantage of the well-established crystal structure of thrombin-aptamer complex, covalent thrombin aptamers containing sulfonyl fluoride ${ }^{34}$ and sulfonamide ${ }^{35}$ warheads were recently developed by rational designs. Unfortunately, the exact structures of RBD-aptamer complex $\frac{9-10}{}$ are still unknown, and RBD-ACE2 as a PPI is much more difficult to inhibit covalently than thrombin as an enzyme. To address the challenge, in this work, we developed covalent aptamer inhibitors of RBD-ACE2 by equipping known RBD aptamers with multiple SuFEx (mSuFEx) modifications. The mSuFExaptamers inhibited RBD-ACE2 via a covalent RBD binding mechanism and showed higher efficiency than the original aptamer.

\section{Results and Discussion}

\section{Chemical synthesis of mSuFEx-aptamers}

We chose to modify two known DNA aptamers, named $6 \mathrm{C} 3^{9}$ and $\mathrm{A} 1, \underline{10}$ which were reported to bind RBD with dissociation constants of about 45 and $28 \mathrm{nM}$, respectively. We utilized an efficient reaction between 4-(bromomethyl)benzenesulfonyl fluoride (Br-SF) and phosphorothioate (PS) under 
a mild condition to introduce mSuFEx (Figure 1a), similar to our previous works on modifying DNA $\underline{36}$ and RNA $\frac{37}{}$ with bromomethyl compounds. $\frac{36-39}{}$ Because the structures of RBD-aptamer complexes were still unknown, we carried out a tail modification strategy and attached an eight-thymidine (8T) fragment containing one or multiple PS modifications to the $3^{\prime}$ end of aptamers (Figure 1a). We successfully incorporated 1, 3, 5, or 7 sulfonyl fluoride (SF) modifications to the 3 ' end 8T on 6C3, as well as 5 or $7 \mathrm{SF}$ to that on A1, as confirmed by the polyacrylamide gel electrophoresis (PAGE) and electrospray ionization-mass spectrometry (ESI-MS) analyses (Figure 1b and 1c).

(a)

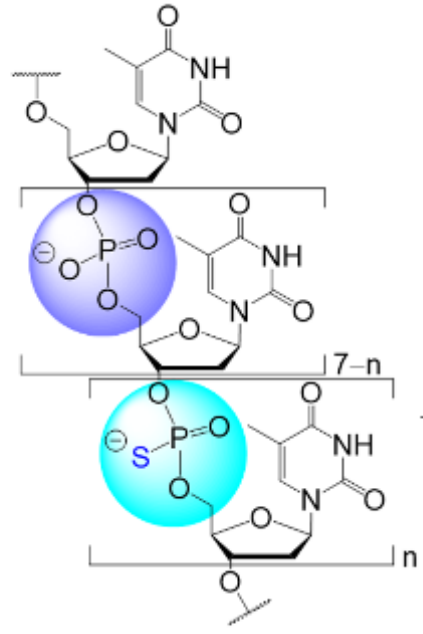

PS-aptamers

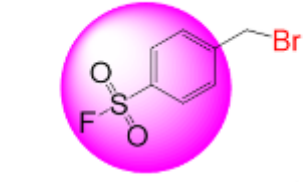

$\mathrm{CH}_{3} \mathrm{CN}, \mathrm{PBS}, 37^{\circ} \mathrm{C}, 1 \mathrm{~d}$

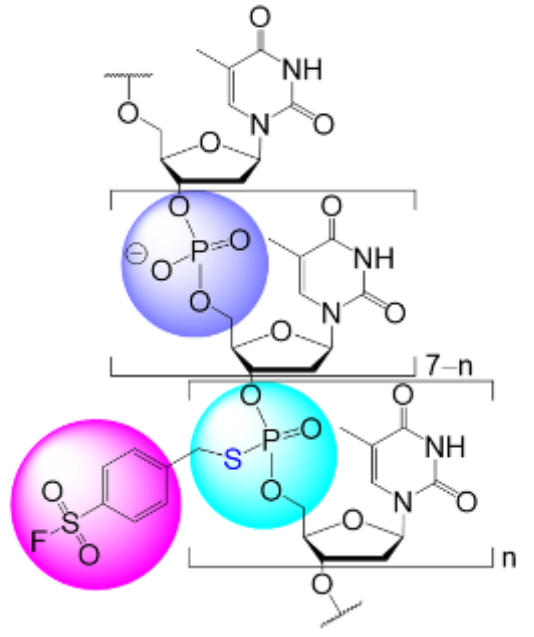

mSuFEx-aptamers

6C3-nT*: CGCAGCACCCAAGAACAAGGACTGCTTAGGATTGCGATAGGTTCGGT ${ }_{7-n} T^{*}{ }_{n}{ }^{\top}$ A1-nT*: TCGAGTGGCTTGTTTGTAATGAGGGTTCCGGTCGTGGGTT $7-n{ }^{*}{ }_{n} T$

(b)

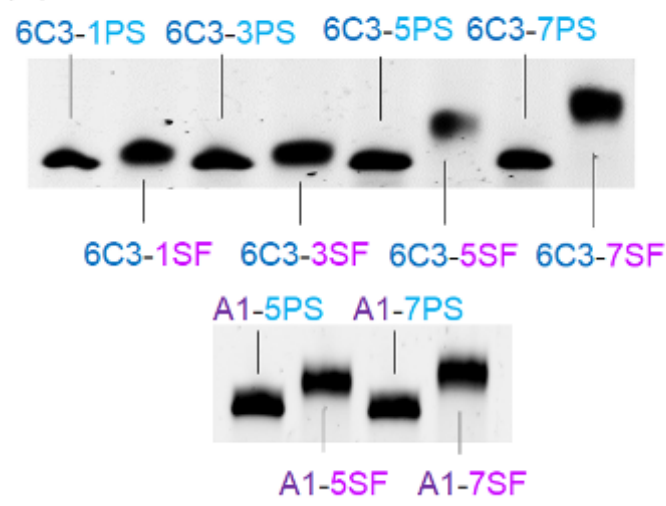

(c)

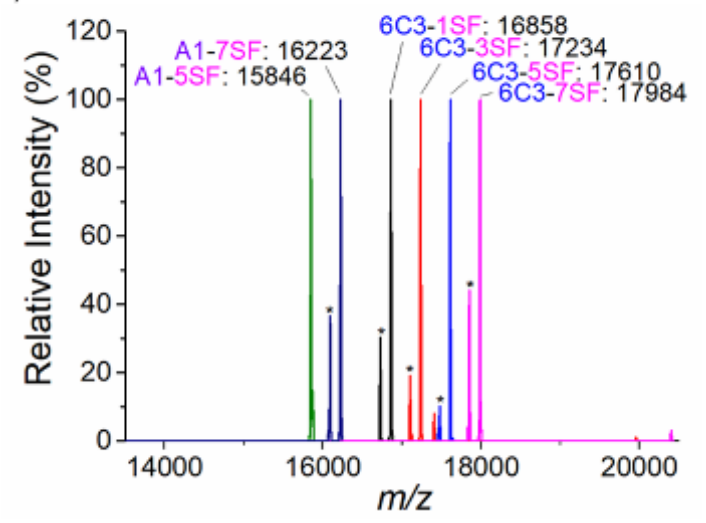

Figure 1. (a) Synthesis of mSuFEx-aptamers, where the asterisks indicate PS for mSuFEx modification. (b) PAGE images of PS-aptamers before and after mSuFEx modification. (c) ESI-MS analyses of aptamers modified with $\mathrm{mSuFEx}$, where the asterisks indicate side peaks of losing one guanine $(\Delta m / z=-134)$ likely generated by the harsher MS ionization process used for $\mathrm{mSuFEx}$ aptamers. Calculated/detected $m / z$ : 6C3-1SF (16855/16858), 6C3-3SF (17231/17234), 6C3-5SF (17607/17610), 6C3-7SF (17983/17984), A1-5SF (15841/15846), A1-7SF (16217/16223). 
(a)

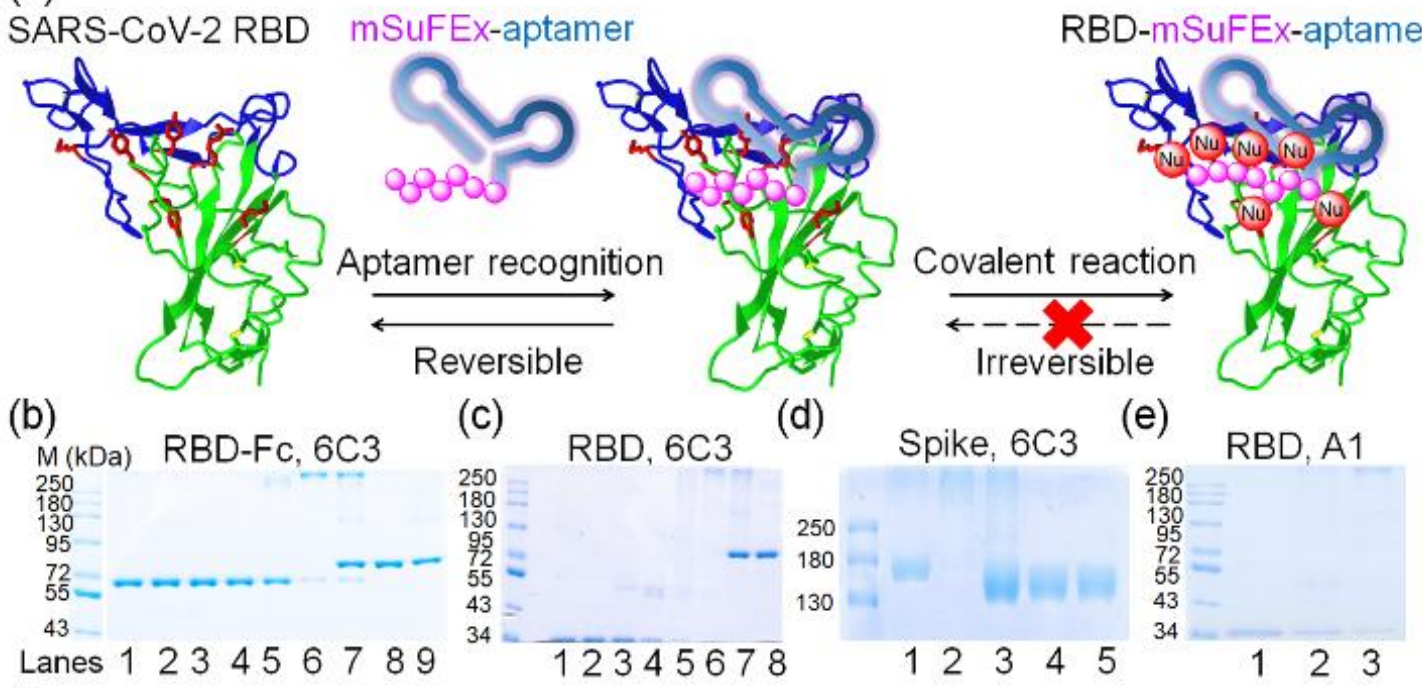

(f)
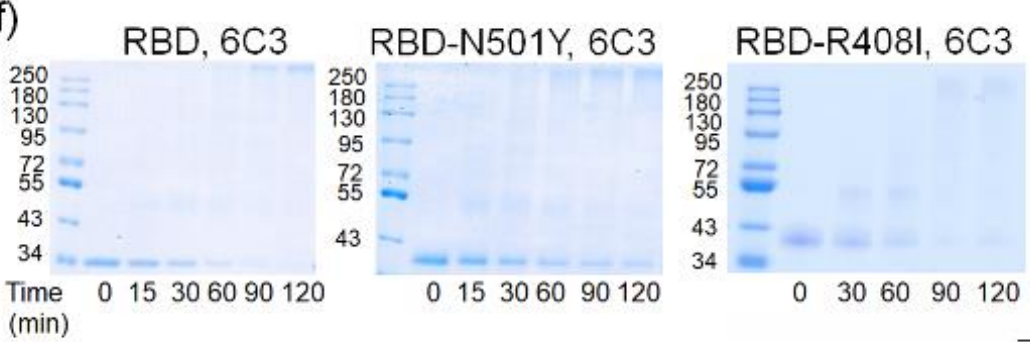

(g)
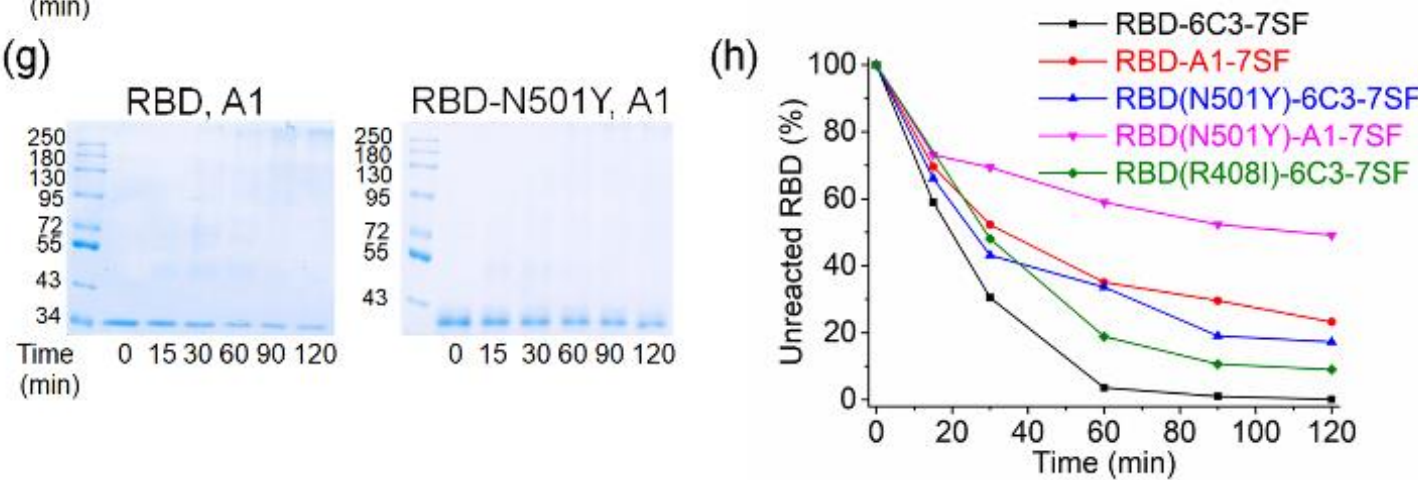

Figure 2. (a) Covalent bonding between RBD and mSuFEx-aptamer involving aptamer recognition and covalent reaction to form RBD-mSuFEX-aptamer. (b) SDS-PAGE of Fc-tag RBD reacted with mSuFEx 6C3 aptamers. Lane 1 9: RBD-Fc; RBD-Fc+6C3-7PS; RBD-Fc+6C3-1SF; RBD-Fc+6C33SF; RBD-Fc+6C3-5SF; RBD-Fc+6C3-7SF; RBD-Fc+6C3-7SF+HSA; HSA; 6C3-7SF+HSA. (c) SDS-PAGE of His-tag RBD reacted with mSuFEx 6C3 aptamers. Lane 1 8: RBD; RBD+6C3-7PS; RBD+6C3-1SF; RBD+6C3-3SF; RBD+6C3-5SF; RBD+6C3-7SF; RBD+6C3-7SF+HSA; 6C37SF+HSA. (d) SDS-PAGE of spike protein reacted with 6C3-7SF. Lane 1 5: Spike; Spike+6C3-7SF; Spike+6C3-7SF+ACE2; ACE2; 6C3-7SF+ACE2. (e) SDS-PAGE of RBD reacted with mSuFEx A1 aptamers. Lane 1 3: RBD; RBD+A1-5SF; RBD+A1-7SF. (f) Kinetics of the covalent binding between RBD variants and 6C3-7SF. (g) Kinetics of the covalent binding between RBD variants and A1-7SF. (h) Data chart of the covalent binding kinetics from (f) and (g). For all the above reactions, $1 \mu \mathrm{M}$ RBD and $1.5 \mu \mathrm{M}$ aptamers were reacted for $2 \mathrm{~h}((\mathrm{~b})-(\mathrm{e}))$ or the indicated time ((f)-(h)) in $1 \times$ phosphate buffer saline (PBS, $\mathrm{pH} 7.4$ ) containing $2 \mathrm{mM} \mathrm{MgCl}_{2}$. 


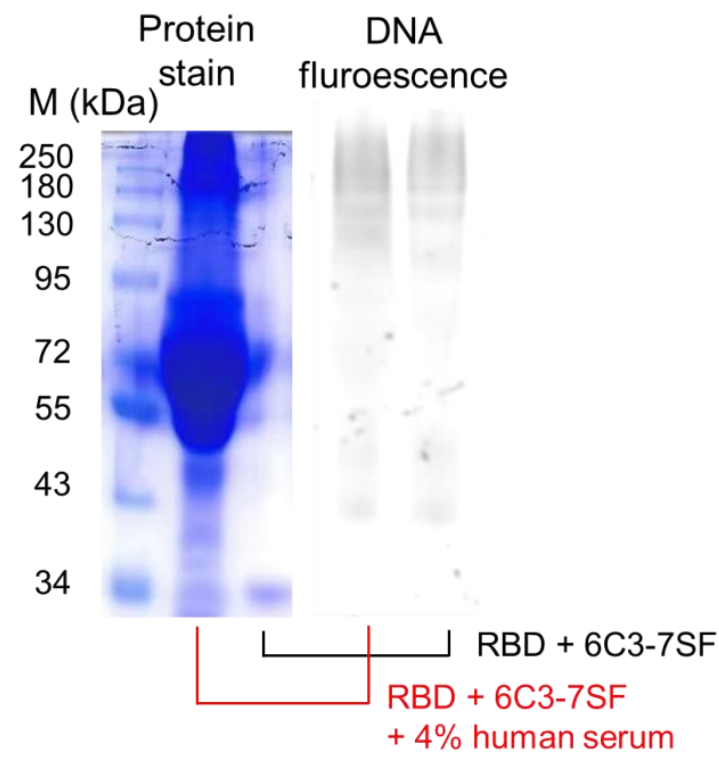

Figure 3. SDS PAGE images of protein stain (left, stained by InstantBlue) and DNA fluorescence (right, no stain, Cy3 channel) showing that the reaction between $400 \mathrm{nM}$ RBD and $100 \mathrm{nM} \mathrm{Cy3-6C3-}$ $7 \mathrm{SF}$ efficiently occurred in the presence of diluted human serum (4\%) in $1 \times \mathrm{PBS}$ containing $2 \mathrm{mM}$ $\mathrm{MgCl}_{2}$ for $2 \mathrm{~h}$ at $37^{\circ} \mathrm{C}$. The serum protein in solution was 100 -fold amount of RBD, showing the good selectivity.

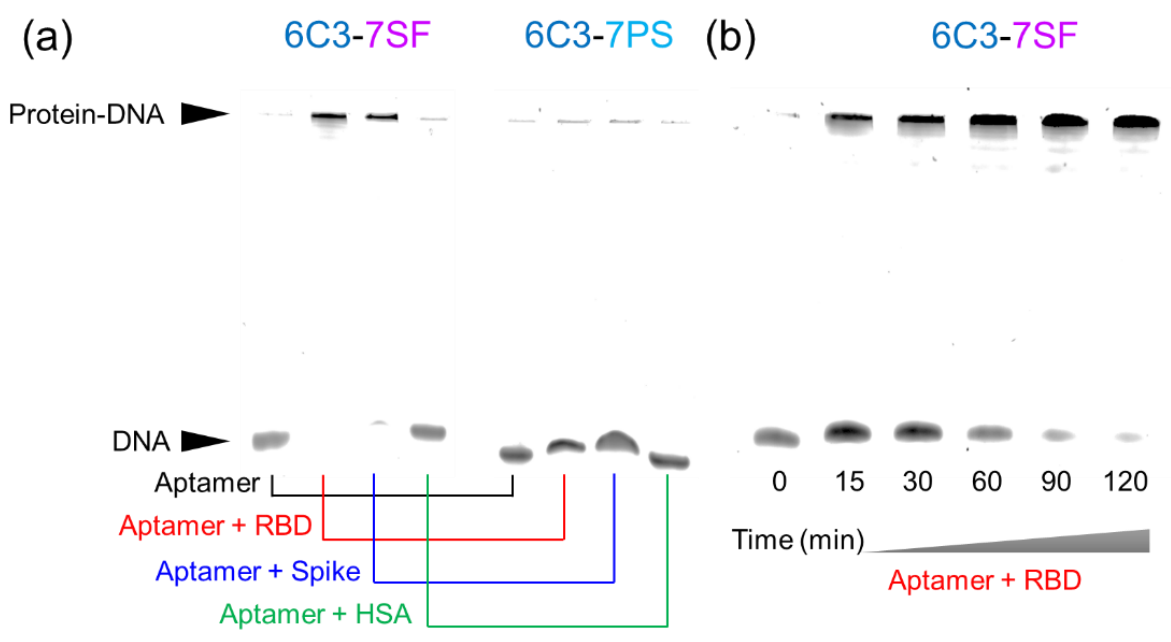

Figure 4. (a) $10 \%$ denatured PAGE of $6 \mathrm{C} 3$ w/wo $7 \mathrm{SF}$ modifications after reaction with different proteins. (b) 10\% denatured PAGE showing the kinetics of 6C3-7SF reacting with RBD. For all the samples, $1 \mu \mathrm{M}$ aptamers (6C3-7SF or 6C3-7PS) were reacted with $1 \mu \mathrm{M}$ proteins in $1 \times \mathrm{PBS}$ containing $2 \mathrm{mM} \mathrm{MgCl} 2$ for $2 \mathrm{~h}$ or indicated time at $37^{\circ} \mathrm{C}$. 


\section{Covalent RBD bonding by mSuFEx-aptamers}

According to sodium dodecyl sulfate-polyacrylamide gel electrophoresis (SDS-PAGE) analyses, efficient covalent bonding with RBD (Figure 2a) was observed for 6C3 aptamers containing 5 or 7 SF modifications, while those with none, 1 , or 3 SF conferred little reaction under the same condition (Figure $2 \mathrm{~b}$ and $2 \mathrm{c}$ ). We tested both Fc-tag and His-tag RBD proteins to exclude the possibility of mere difference in tag reactivity. The cross-linked adducts with large molecular weights $(>250 \mathrm{kDa})$ were formed, which was not surprising considering that multiple potential reactive sites were on both RBD and mSuFEx-aptamers. The spike protein (Spike) containing RBD was found active in covalently bonding with 6C3-7SF as well (Figure 2d). The covalent reaction between mSuFEx-aptamers and RBD/Spike was highly selective over human serum albumin (HSA) and ACE2 (Figure 2b-2d), and occurred efficiently in diluted human serum (Figure 3), indicating the essential role of aptamer recognition. A1 aptamers equipped with 5 or $7 \mathrm{SF}$ also showed covalent binding activities to RBD (Figure 2e), suggesting that RBD aptamers could be generally modified with mSuFEx for covalent RBD binding. Monitoring the kinetics of covalent binding between 6C3-7SF and the RBD variants gave reaction half time $\left(\mathrm{t}_{1 / 2}\right)$ about $\mathrm{t}_{1 / 2}(\mathrm{RBD}-6 \mathrm{C} 3-7 \mathrm{SF})=20 \mathrm{~min}, \mathrm{t}_{1 / 2}(\mathrm{RBD}-\mathrm{N501Y}-6 \mathrm{C} 3-7 \mathrm{SF})=26 \mathrm{~min}$, and $\mathrm{t}_{1 / 2}(\mathrm{RBD}-$ $\mathrm{R} 408 \mathrm{I}-6 \mathrm{C} 3-7 \mathrm{SF})=29 \mathrm{~min}$ (Figure $2 \mathrm{f}$ and $2 \mathrm{~h}$ ) in the presence of a 1.5-fold amount of RBD. These rates were

comparable to the reported covalent thrombin aptamers based on SuFEx chemistry. $\frac{34-35}{\text { It was clearly }}$ observed that RBD was first modified by one 6C3-7SF and then formed the large cross-linked adducts (Figure 2f). We detected slower rates of covalent bond formation between A1-7SF and the RBD variants, with about $\mathrm{t}_{1 / 2}(\mathrm{RBD}-\mathrm{A} 1-7 \mathrm{SF})=35 \mathrm{~min}$ and $\mathrm{t}_{1 / 2}(\mathrm{RBD}-\mathrm{N} 501 \mathrm{Y}-\mathrm{A} 1-7 \mathrm{SF})=115 \mathrm{~min}$ (Figure $2 \mathrm{~g}$ and $\left.2 \mathrm{~h}\right)$. The different reactivities of $6 \mathrm{C} 3-7 \mathrm{SF}$ and A1-7SF toward RBD was understandable because the better binder might not be better at covalent bonding as well. In addition to SDS-PAGE, urea-denatured PAGE analyses visualizing the DNA components also supported the successful covalent bonding between 6C3-7SF and RBD (Figure 4). Protein-DNA adducts were too large to migrate efficiently in denatured PAGE without SDS, so they accumulated at the top of the gels and were stained by DNAstaining dyes. 
(a) RBD-mSuFEx-aptamer

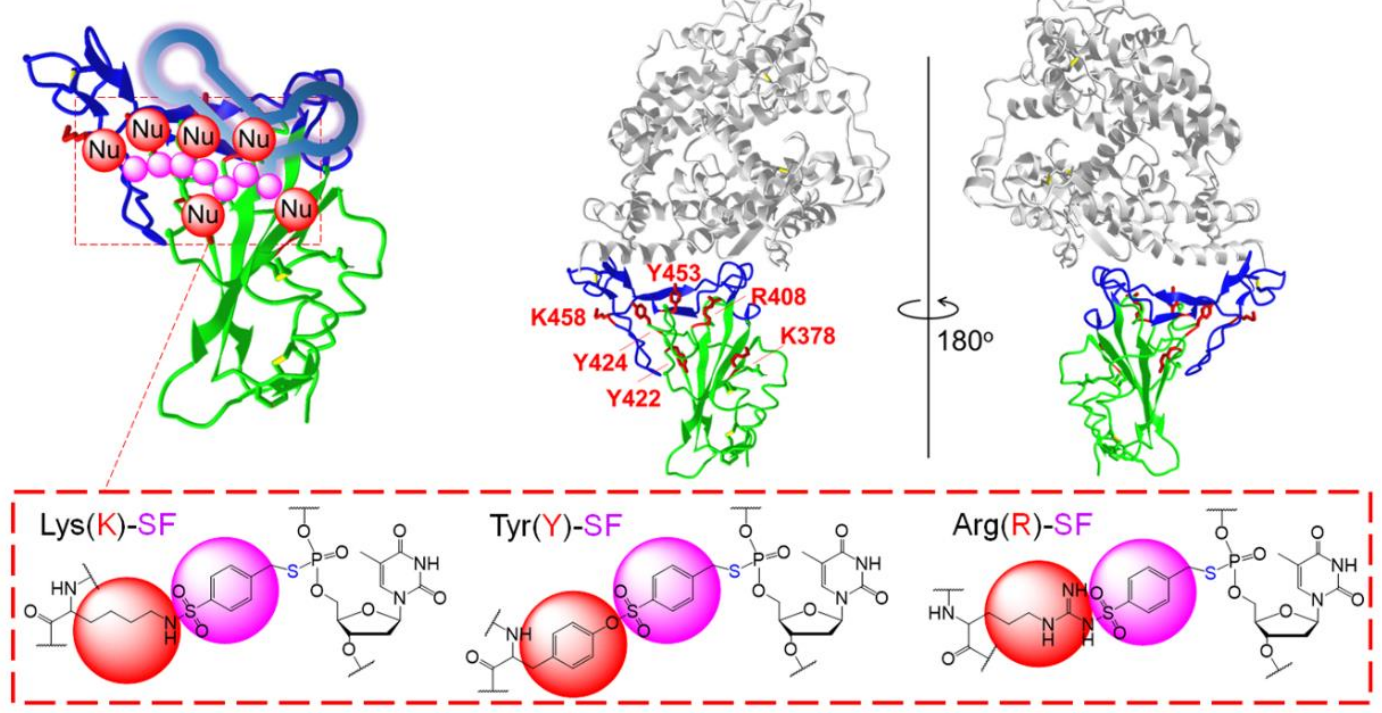

(b)

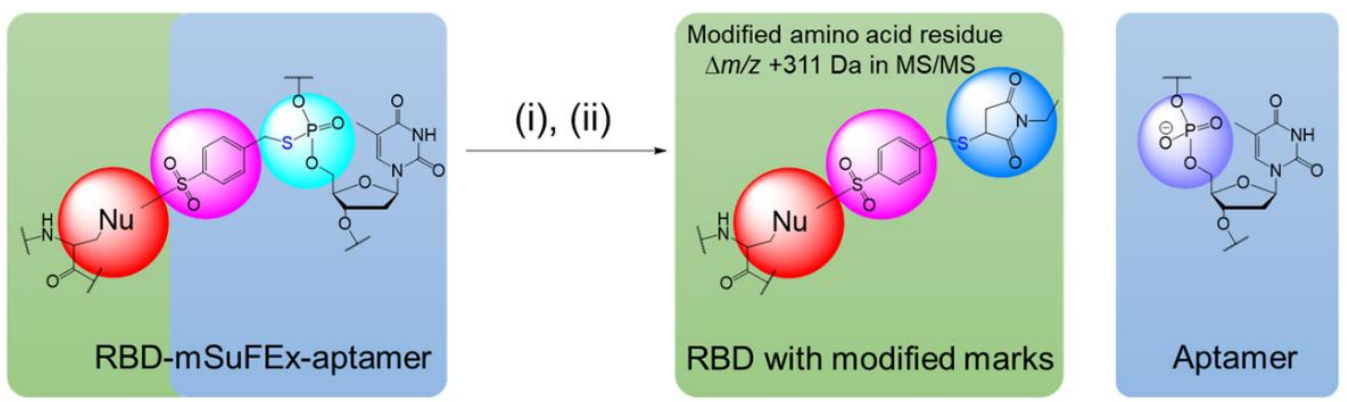

(c) 319-368 RVQPTESIVRFPNITNLCPFGEVFNATRFASVYAWNRKRISNCVADYSVL 369-418 YNSASFSTFKCYGVSPTKLNDLCFTNVYADSFVIRGDEVRQIAPGQTGKI 419-468 ADYNYKLPDDFTGCVIAWNSNNLDSKVGGNYNYLYRLFRKSNLKPFERDI 469-518 STEIYQAGSTPCNGVEGFNC YFPLQSYGFQPTNGVGYQPYRVVVLSFELL 519-540 HAPATVCGPKKSTNLVKNKCVNF

Figure 5. (a) Covalent bonding sites in RBD-6C3-7SF as identified by LC-MS/MS, revealing K378, R408, Y422, Y424, Y453, and K458. The structures of SF-modified lysine (Lys), tyrosine (Tyr), and arginine (Arg) are in the red dash-line rectangle. In RBD-ACE2, RBM of RBD, non-RBM of RBD, and ACE2 are shown in blue, green, and gray, respectively. (b) Procedure of removing DNA aptamer from RBD-6C3-7SF and subsequent reduction and blocking of thiols for the MS/MS analysis: i, 100 $\mathrm{mM} \mathrm{NaOH}, 0.5 \mathrm{~h}$; ii, $2 \mathrm{mM}$ DTT, $1 \mathrm{~h}$, then $10 \mathrm{mM}$ N-ethylmaleimide, $1 \mathrm{~h}$. (c) Amino acid sequence of RBD and the detected peptide fragments by MS/MS. RBM residues are in blue and underlined. Non-RBM residues are in green. SF-modified residues are in red. Yellow and gray-highlighted peptide fragments are w/wo covalent bonding sites (red) with high confidence, respectively. See Figure 6a-f for MS/MS spectra assigning the covalent bonding sites. 


\section{Covalent bonding sites in RBD-6C3-7SF adducts}

We investigated the covalent bonding sites in RBD-6C3-7SF adducts (Figure 5a) by liquid chromatography coupled with tandem mass spectrometry (LC-MS/MS) analysis. DNA aptamers were removed from $\mathrm{RBD}-6 \mathrm{C} 3-7 \mathrm{SF}$ by $\mathrm{NaOH}$ treatment to hydrolyze the phosphorothioate ester, leaving thiol-containing sulfonyl marks on the proteins. These marks, along with RBD cysteines, were treated with the disulfide reduction using DL-dithiothreitol (DTT) and the blocking protocol using $\mathrm{N}$ ethylmaleimide, and the proteins were then digested by trypsin and the resulting peptides were analyzed by LC-MS/MS (Figure 5b). By manual inspection of MS/MS spectra of interest generated by Proteome Discoverer 2.4 software to confirm peptide sequences and modification sites, we identified K378, R408, Y422, Y424, Y453, and K458 of RBD as the covalent bonding sites in RBD6C3-7SF (Figure 5c) with high confidence, showing the detected mass of the covalent bonding residues calculated from the fragments matching the theoretical values very well (Figure 6a-f). The peptide fragments in the MS/MS spectra assigning R408 (Figure 6b) and Y453 (Figure 6e) were much cleaner than those for K378 (Figure 6a), Y422 (Figure 6c), Y424 (Figure 6d) and K458 (Figure 6f), indicating that R408 and Y453 might be the major covalent bonding site, though it was too arbitrary to make such a conclusion according to solely the MS/MS data from peptide fragments that were generated by trypsin digestion with unpredictable yields. In comparison, only when reacting $1 \mu \mathrm{M}$ RBD with $p$ toluenesulfonyl fluoride at a high concentration of $5 \mathrm{mM}$ (versus $1.5 \mu \mathrm{M} 6 \mathrm{C} 3-7 \mathrm{SF}$ ), we were able to detect and verify covalent reaction solely at K458 (Figure 7). 
(a)

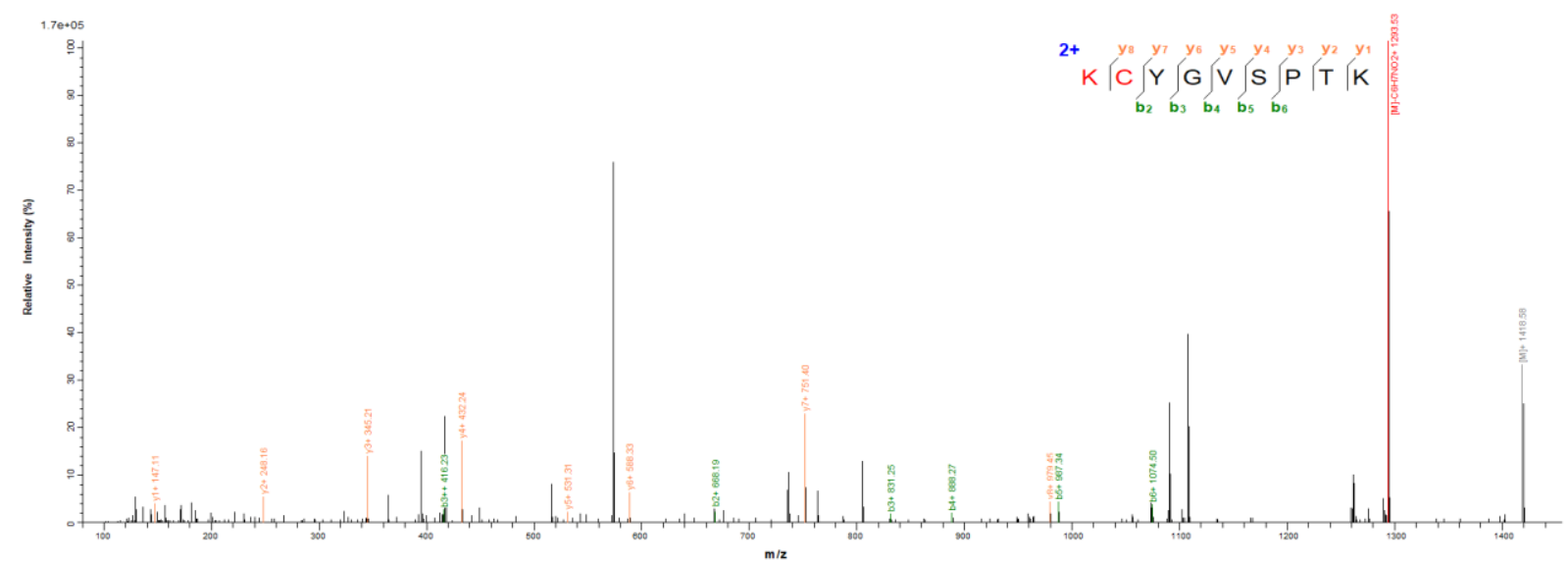

(b)

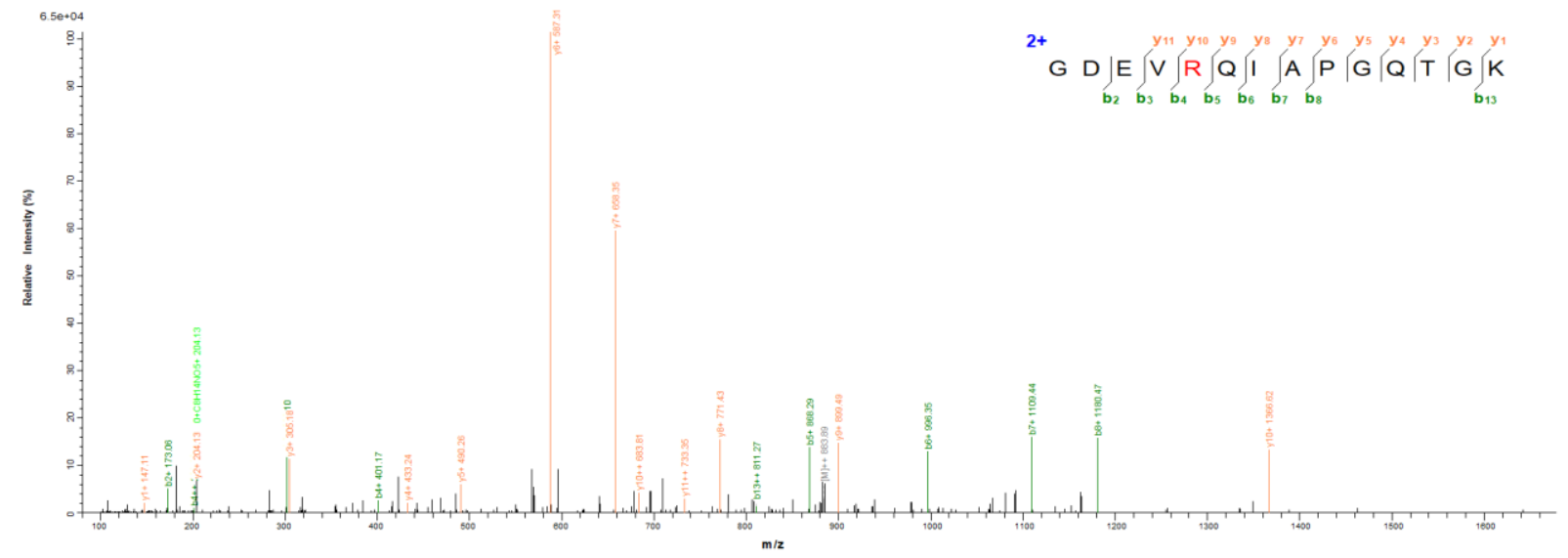

(c)

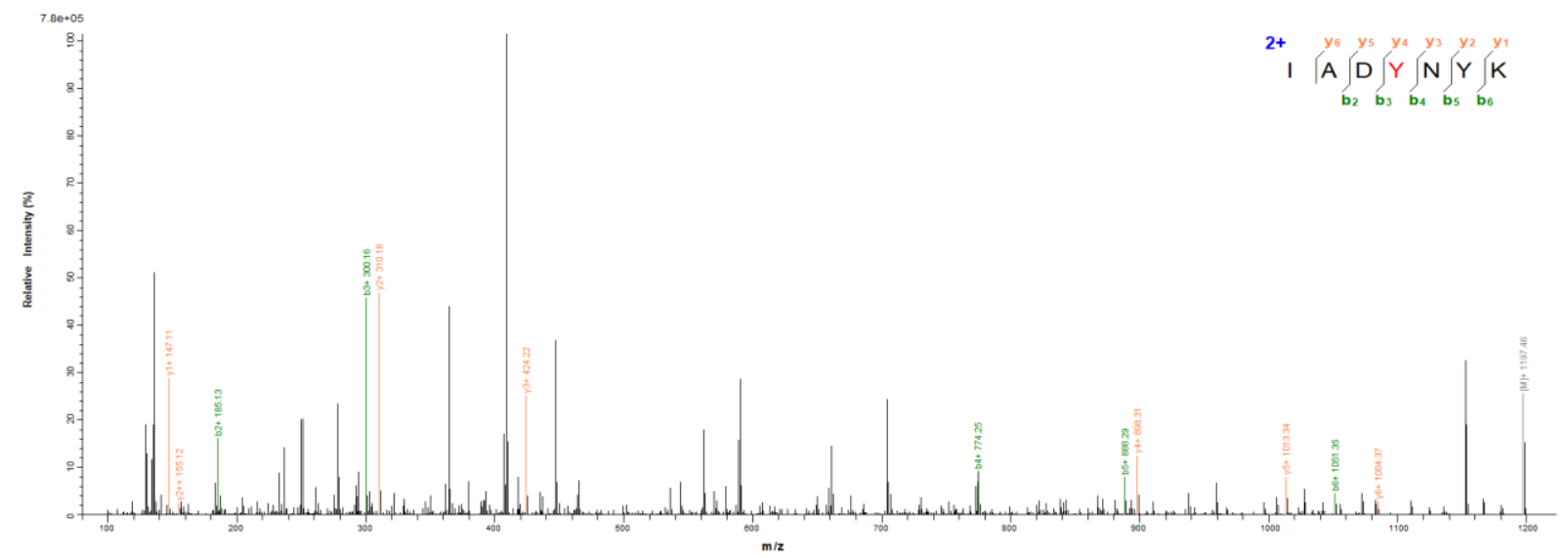

Figure 6a-c. Peptide fragmentation MS/MS showing the modification of K378 (a), R408 (b), and Y422 (c) in RBD-6C3-7SF adducts. The red cysteine (C) in (a) is modified with N-ethylmaleimide and gives $\Delta m / z=\mathrm{y} 8-\mathrm{y} 7=228.05$ that is the molecular weight of cysteine $-\mathrm{H}_{2} \mathrm{O}+\mathrm{N}$-ethylmaleimide (calc. 228.06). The red lysine (K) in (a), arginine (R) in (b), and tyrosine (Y) in (c) are modified with sulfonyl-CH $\mathrm{CH}_{2}-\mathrm{S}-\mathrm{N}$-ethylmaleimide (SSNEM) and gives $\Delta m / z=\mathrm{M}-\mathrm{y} 8=439.13$ (lysine $-\mathrm{H}_{2} \mathrm{O}+\mathrm{SSNEM}$, calc. 439.12 ) in (a), $\Delta m / z=\mathrm{y} 10-\mathrm{y} 9=467.13$ and b5-b4 $=467.12$ (arginine $-\mathrm{H}_{2} \mathrm{O}+\mathrm{SSNEM}$, calc. 467.13 ) in (b), and $\Delta m / z=y 4-y 3=474.09$ and b4-b3 = 474.09 (tyrosine $-\mathrm{H}_{2} \mathrm{O}+\mathrm{SSNEM}$, calc. 474.09) in (c), respectively. 
(d)

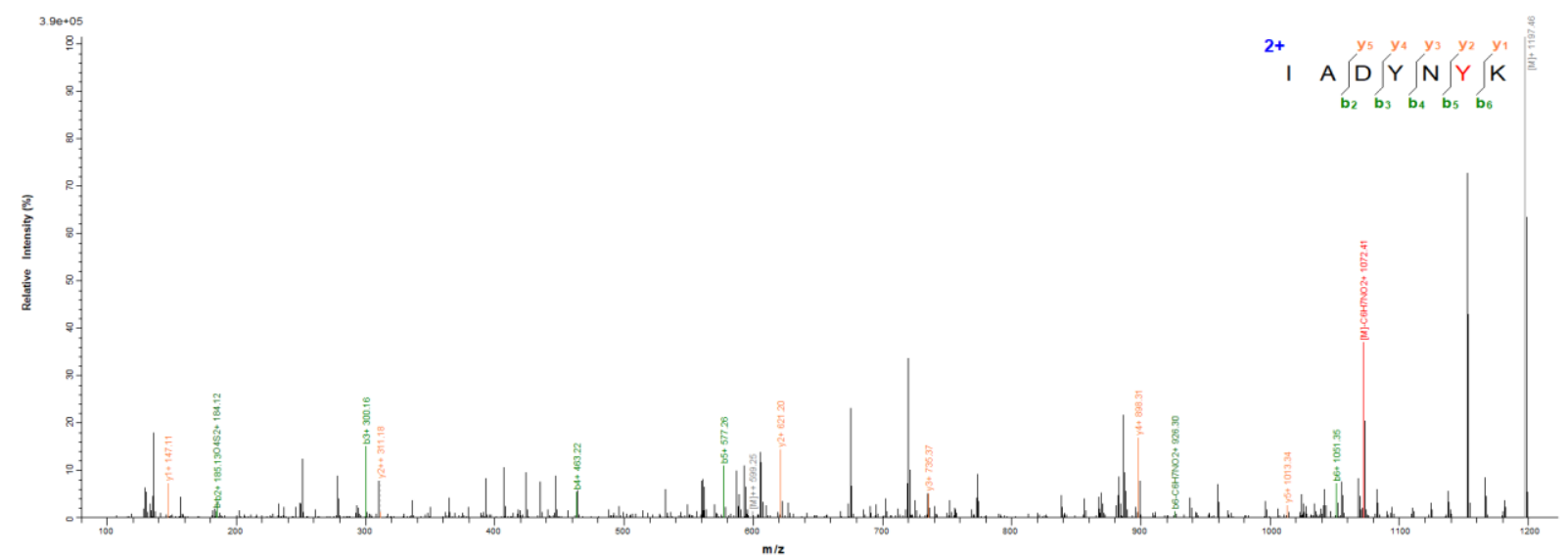

(e)

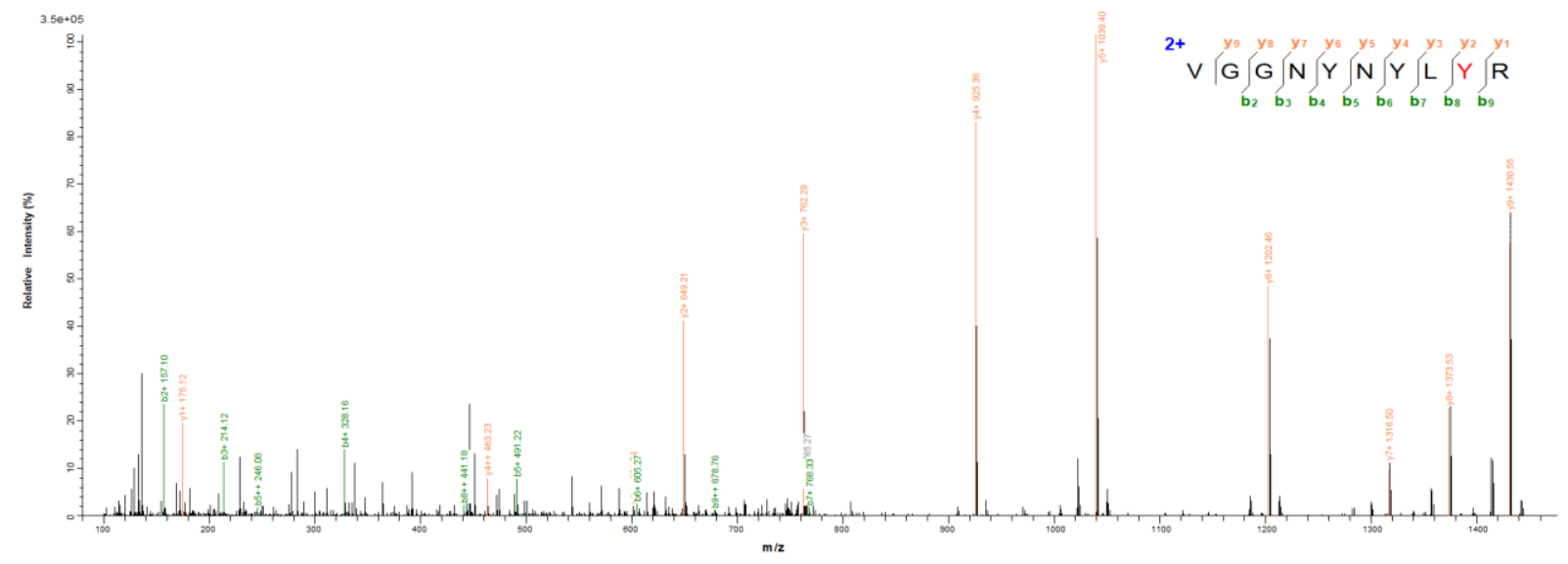

(f)

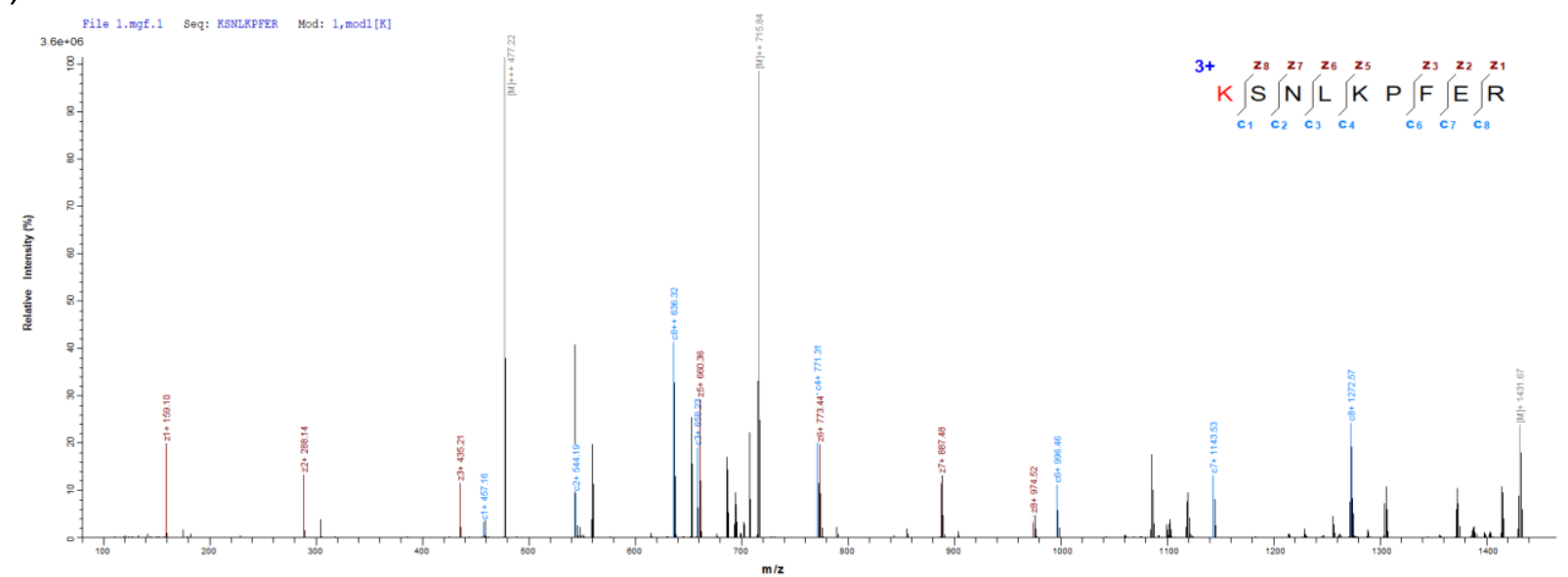

Figure 6d-f. Peptide fragmentation MS/MS showing the modification of Y424 (d), Y453 (e), and K458 (f) in RBD-6C3-7SF adducts. The red tyrosine (Y) in (d), tyrosine (Y) in (e), and lysine (K) in (f) are modified with sulfonyl- $\mathrm{CH}_{2}-\mathrm{S}-\mathrm{N}$-ethylmaleimide (SSNEM) and gives $\Delta m / z=\mathrm{y} 2-\mathrm{y} 1=474.09$ and b6-b5 = 474.09 (tyrosine $-\mathrm{H}_{2} \mathrm{O}+\mathrm{SSNEM}$, calc. 474.09) in (d), $\Delta m / z=\mathrm{y} 2-\mathrm{y} 1=474.09$ (tyrosine- $\mathrm{H}_{2} \mathrm{O}+\mathrm{SSNEM}$, calc. 474.09) in (e), and $\Delta m / z=\mathrm{M}-\mathrm{z} 8=457.15$ and $\mathrm{c} 1=457.16$ (lysine+SSNEM, calc. 457.13) in (f), respectively. 


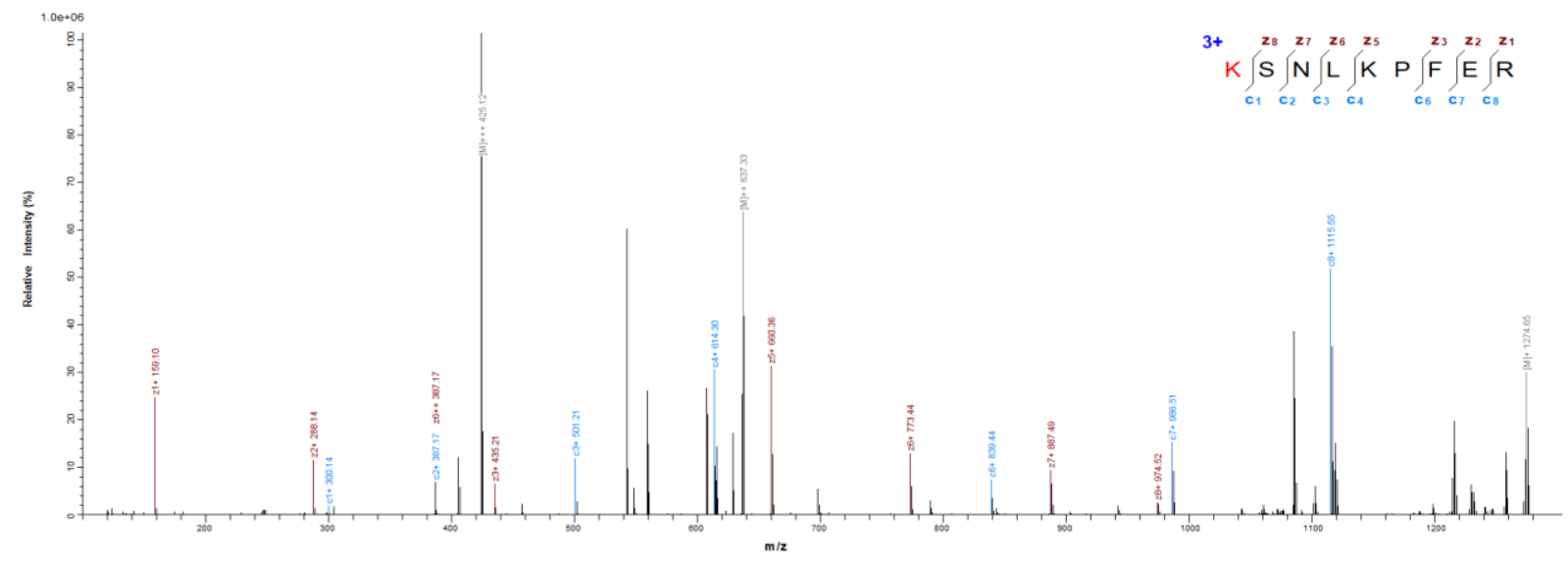

Figure 7. Peptide fragmentation MS/MS showing the modification of K458 in RBD after reaction with $5 \mathrm{mM} p$-toluenesulfonyl fluoride. The red tyrosine lysine $(\mathrm{K})$ is modified with $p$-toluenesulfonyl and gives $\Delta m / z=\mathrm{M}-\mathrm{z} 8=300.13$ and $\mathrm{c} 1=300.14$ (lysine $+p$-toluenesulfonyl, calc. 300.11 ).

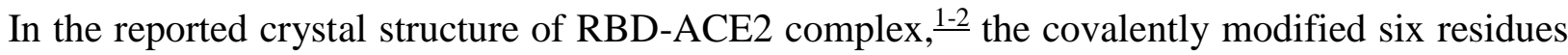
are on one side of RBD and relatively close to each other (Figure 5a). Such a pattern strongly indicates that $6 \mathrm{C} 3-7 \mathrm{SF}$ binds $\mathrm{RBD}$ and positions the mSuFEx modifications in proximity to the six RBD residues (Figure 5a). R408 and Y453 directly interact with N90 glycan and H34 of ACE2. $\stackrel{1-2}{ }$ The other four are either within (K458) or close (K378, Y422, Y424) to the important receptor-binding motif (RBM) of RBD (Figure 5a). The capability of targeting multiple RBD residues by 6C3-7SF is beneficial to enhance RBD-ACE2 inhibition as well as potentially tolerates RBD mutations in SARSCoV-2 variants. $\stackrel{40-41}{ }$

Lysine and tyrosine residues are known potential targets of SuFEx warheads such as SF. $\underline{28}$ Surprisingly, R408, a non-N-terminal arginine residue, is an SF-reactive residue in our study (Figure 6b). The fragmentation MS/MS of the peptide containing R408 strongly excluded the possibility of Nterminal sulfonylation of R408 (Figure 6b), leaving only the guanidinium side chain as the potential SF-reactive site. To the best of our knowledge, no previous work identified any non-N-terminal arginine reactive to SuFEx warheads, and we showed that the guanidinium side chain of a contextspecific arginine could react with SuFEx-based covalent inhibitors, though probably the mSuFEx is necessary for the higher reactivity over a monomeric SuFEx warhead. In fact, sulfonylation of arginine side chain was not uncommon in organic synthesis, where sulfonyl electrophiles stronger than SF were used for such a reaction in organic solvents. And, aryl sulfonylated arginine derivatives were routine building blocks for solid-phase synthesis of peptides. $\frac{42-43}{3}$ They indicate that the formation of 
sulfonylated arginine from 6C3-7SF and RBD should be thermodynamically favored. The mSuFEx of 6C3-7SF is in principle more reactive than monomeric SuFEx warheads. In addition, the adjacent D405 and E406 can both provide carboxyl groups to activate the guanidinium of R408, similarly to the active site residues of arginine methyltransferases. $\frac{44}{}$ These factors may contribute to the observed reactivity of 6C3-7SF toward R408. Interestingly, R408 is highly conserved in SARS-CoV-2 variants of concern and variants of interest (https://www.who.int/en/activities/tracking-SARS-CoV-2-variants/), and it plays an important role in RBD-ACE2 through binding with the N90 glycan of ACE2, suggesting that R408 could be the covalent bonding site of interest for developing SuFEx-based covalent inhibitors against the RBD mutants of threatening SARS-CoV-2 variants.

(a) RBD active

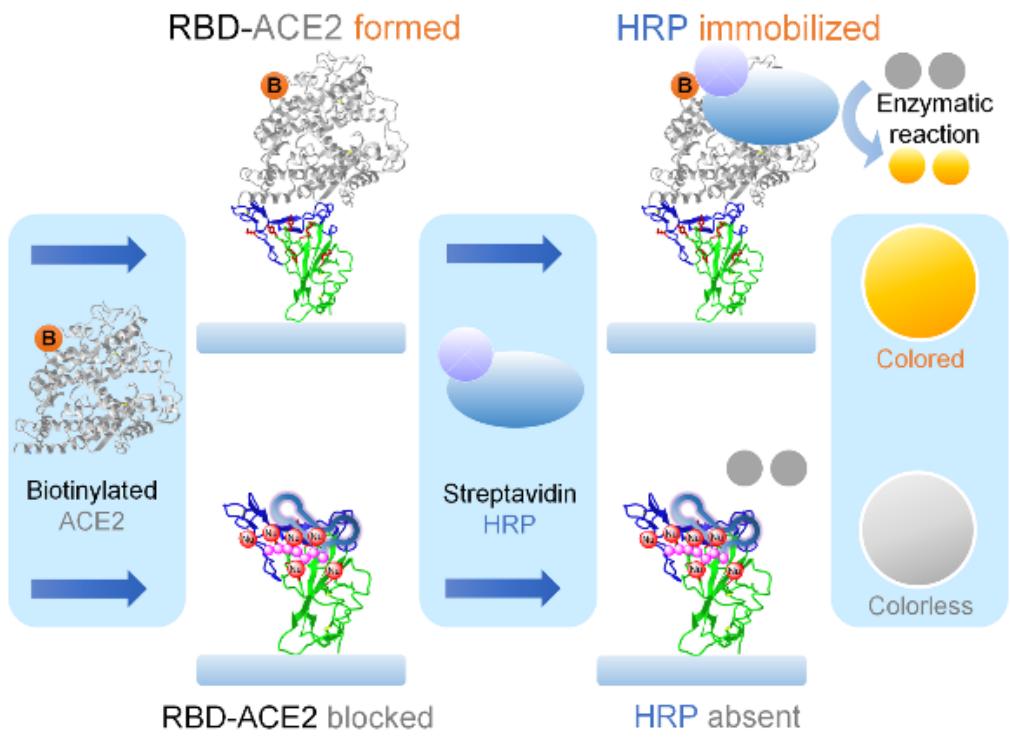

(b)
RBD inhibited
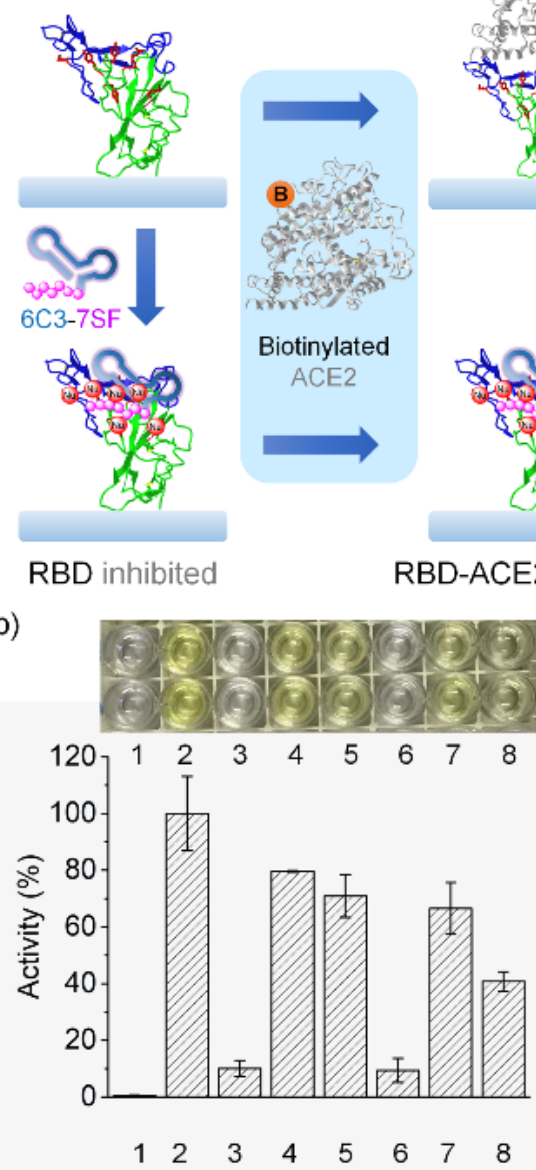

(c)

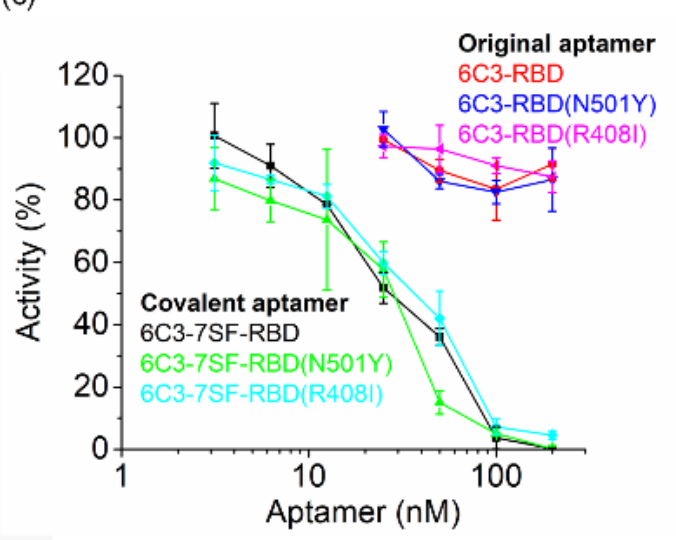

Figure 8. (a) ELISA measuring RBD-ACE2 inhibition by 6C3-7SF. (b) RBD-ACE2 inhibition by different aptamers. Sample 1 8: blank (no RBD); negative control (no aptamer); positive control (500 $\mathrm{nM}$ inhibitor from the ELISA kit); $200 \mathrm{nM} \mathrm{6C3;} 200 \mathrm{nM} 6 \mathrm{C3}-1 \mathrm{SF} ; 200 \mathrm{nM} 6 \mathrm{C} 3-7 \mathrm{SF} ; 1 \mu \mathrm{M} 6 \mathrm{C} 3 ; 2$ $\mu \mathrm{M} 6 \mathrm{C} 3$. (c) RBD-ACE2 inhibition activities of $6 \mathrm{C} 3$ with or without 7SF modifications against RBD, RBD-N501Y and RBD-R408I. 


\section{Covalent inhibition of RBD-ACE2 by 6C3-7SF}

Encouraged by the efficient and selective covalent bonding between RBD and mSuFEx-aptamers, we then set to measure the covalent inhibition of RBD-ACE2 by 6C3-7SF. We utilized a commercially available enzyme-linked immunosorbent assay (ELISA) to assess the RBD-ACE2 inhibitory efficacy (Figure 7a). $\stackrel{45}{ }$ The original $6 \mathrm{C} 3$ had only a weak inhibition activity at even $200 \mathrm{nM}$, and 1SF modification was unable to provide apparent improvement (Figure 7b), in agreement with our SDSPAGE results showing that $1 \mathrm{SF}$ was insufficient for covalent bond formation with RBD (Figure $2 \mathrm{~b}$ and 2c). In contrast, dramatic enhancement of RBD-ACE2 inhibition was observed for $200 \mathrm{nM}$ 6C3-7SF (Figure $7 b$ ), demonstrating the advantage of endowing a covalent inhibition mechanism. We detected the half-maximal inhibitory concentration $\left(\mathrm{IC}_{50}\right)$ as low as $\mathrm{IC}_{50}(\mathrm{RBD})=26 \pm 2, \mathrm{IC}_{50}(\mathrm{RBD}-\mathrm{N} 501 \mathrm{Y})=28 \pm 5$, and $\mathrm{IC}_{50}(\mathrm{RBD}-\mathrm{R} 408 \mathrm{I})=37 \pm 7 \mathrm{nM}$ for $6 \mathrm{C} 3-7 \mathrm{SF}$ when blocking the variant RBD-ACE2 (Figure 7c), suggesting a general inhibitory effect of $6 \mathrm{C} 3-7 \mathrm{SF}$ against the variants. The original $6 \mathrm{C} 3$, on the other hand, had $\mathrm{IC}_{50}$ well above $200 \mathrm{nM}$ for all the RBD variants tested.

\section{Conclusion}

In summary, we constructed covalent RBD-ACE2 inhibitors through equipping known RBD aptamers with mSuFEx modifications up to 7. The mSuFEx-aptamer 6C3-7SF showed strong covalent bonding with RBD and its variants (RBD-N501Y and RBD-R408I) at a high selectivity over serum proteins and ACE2. ELISA in vitro demonstrated stronger RBD-ACE2 inhibition by 6C3-7SF than the original $6 \mathrm{C} 3$, indicating the advantage of introducing a covalent inhibition mechanism. We believe that, like peptides and proteins, $\underline{23-26}$ aptamers can also be converted into efficient covalent PPI inhibitors to offer inhibition with higher potency and longer duration, and the mSuFEx strategy described here for RBD-ACE2 inhibition is just one example of this promising field. The compatibility of mSuFEx-based covalent aptamers in cellular and in vivo systems is now under investigation in our lab by optimizing them through the chemical toolbox well established in oligonucleotide drugs including antisense oligonucleotide (ASO) ${ }^{46}$ and small interfering RNA (siRNA). ${ }^{47}$ 


\section{Experimental Section}

\section{Materials}

Chemicals for buffers and polyacrylamide gels were from either Sigma Aldrich (Shanghai, China) or Alfa Aesar (Tianjin, China). Reagents for chemical reactions, including 4(bromomethyl)benzenesulfonyl fluoride (Br-SF), p-toluenesulfonyl fluoride, DL-dithiothreitol (DTT), N-ethylmaleimide, sodium hydroxide and acetonitrile were purchased from Sigma Aldrich (Shanghai, China). ACE2 (Cat\# 10108-H02H), Spike protein (Cat\# 40591-V08H), Fc-tag RBD (Cat\# 40150V05H), His-tag RBD (Cat\# 40150-V08B2), RBD-N501Y (Cat\# 40592-V08H82) were from Sino Biological (Beijing, China). We also purchased RBD (Cat\# SPD-C52H2) and RBD-R408I (Cat\# SPDS52H8) from Acro Biosystems (Beijing, China). Human serum albumin (HSA) and human serum were from Sigma Aldrich (Shanghai, China). Sequence grade trypsin (Cat\# V5113) was from Promega (Beijing, China). Amicon Ultra centrifugal filters (Amicon-10K) were from Merck KGaA (Darmstadt, Germany). The SARS-CoV-2 inhibitor screening kit (Cat\# EP-105) and ELISA reagent set (Cat\# EBS001) were from Acro Biosystems (Beijing, China). All the oligonucleotides were purchased from Integrated DNA Technologies (IA, USA), Genscript (Jiangsu, China) or Hippobio (Zhejiang, China).

Table 1. List of DNA aptamers used in this work.

\begin{tabular}{|l|l|}
\hline Name & Sequence (left to right: $\mathbf{5}^{\prime}$ to $\mathbf{3}^{\prime}$ ) \\
\hline 6C3 & CGCAGCACCCAAGAACAAGGACTGCTTAGGATTGCGATAGGTTCGG \\
\hline 6C3-1PS & CGCAGCACCCAAGAACAAGGACTGCTTAGGATTGCGATAGGTTCGGTTTTTTT*T \\
\hline 6C3-3PS & CGCAGCACCCAAGAACAAGGACTGCTTAGGATTGCGATAGGTTCGGTTTTT*T*T*T \\
\hline 6C3-5PS & CGCAGCACCCAAGAACAAGGACTGCTTAGGATTGCGATAGGTTCGGTTT*T*T*T*T*T \\
\hline 6C3-7PS & CGCAGCACCCAAGAACAAGGACTGCTTAGGATTGCGATAGGTTCGGT*T*T*T*T*T*T*T \\
\hline A1-5PS & TCGAGTGGCTTGTTTGTAATGTAGGGTTCCGGTCGTGGGTTTT*T*T*T*T*T \\
\hline A1-7PS & TCGAGTGGCTTGTTTGTAATGTAGGGTTCCGGTCGTGGGTT*T*T*T*T*T*T*T \\
\hline Cy3-6C3-7PS & Cy3-CGCAGCACCCAAGAACAAGGACTGCTTAGGATTGCGATAGGTTCGGT*T*T*T*T*T*T*T \\
\hline
\end{tabular}

\section{Synthesis of SF-modified aptamers}

SF-modified aptamers, including mSuFEx-aptamers, was prepared by reacting Br-SF with PScontaining aptamers shown in Table S1. To a $50 \mu \mathrm{L}$ solution of $100 \mu \mathrm{M}$ PS-containing aptamers in 100 $\mathrm{mM}$ sodium phosphate buffer at $\mathrm{pH} 6.0$ was added $50 \mu \mathrm{L} 30 \mathrm{mM}$ Br-SF in $\mathrm{CH}_{3} \mathrm{CN}$. The solution was kept at $37^{\circ} \mathrm{C}$ for 1 day. The resulting solution was combined with $200 \mu \mathrm{L}$ water and extracted by 200 
$\mu \mathrm{L}$ butanol twice. The bottom (water) phase was purified by Amicon-10K ultrafilters using water for 6 times. The concentration of the final SF-modified aptamer solution was quantified by the standard UV260 method, and the stock solution was diluted to desired concentrations for other experiments. Denatured polyacrylamide gel electrophoresis (PAGE) and electrospray ionization (ESI)-ion trap mass spectrometry (MS) were used for characterizing the SF-modified aptamer products. The ESI-MS measurement was provided by Genscript (Beijing, China) or performed on a Thermo Scientific LTQ $\mathrm{XL}^{\mathrm{TM}}$ Linear Ion Trap MS at Tsinghua University. Upon storage at $-20^{\circ} \mathrm{C}$, the BSF-modified aptamer products were found stable in stock solution for at least 1 months.

\section{Denatured PAGE analysis of aptamers before and after reaction with proteins}

For the data shown in Figure 1b, aptamer samples dissolved in $1 \times$ PBS were mixed with 2 -fold volume of $8 \mathrm{M}$ urea, and were electrophoresed at $200 \mathrm{~V}$ for around $1 \mathrm{~h}$ on $10 \%$ denatured polyacrylamide gels (29:1 monomer to bis ratio, $8 \mathrm{M}$ urea) in 1×TBE running buffer (90 mM Tris, 90 $\mathrm{mM}$ boric acid, $2 \mathrm{mM} \mathrm{Na} 2$ EDTA, $\mathrm{pH}$ 8.3) using the vertical electrophoretic apparatus (DYY-6C, Liuyi Instrument Factory, Beijing, China). After SYBR Gold (1×) staining, the gels were visualized using a Biorad Gel Doc XR+ Gel Documentation System.

For the data shown in Figure 4, $1 \mu \mathrm{M}$ aptamers (6C3-7SF or 6C3-7PS) were reacted with $1 \mu \mathrm{M}$ proteins in $1 \times \mathrm{PBS}$ containing $2 \mathrm{mM} \mathrm{MgCl}$ for $2 \mathrm{~h}$ or indicated time at $37{ }^{\circ} \mathrm{C}$. Then the solutions were mixed with $8 \mathrm{M}$ urea and analysed by $10 \%$ denatured PAGE using the same condition as above.

\section{SDS-PAGE analysis of proteins before and after reaction with aptamers}

For the SDS-PAGE data shown in Figure 2, $1 \mu \mathrm{M}$ proteins were reacted with $1.5 \mu \mathrm{M}$ aptamers for $2 \mathrm{~h}$ or indicated time at $37^{\circ} \mathrm{C}$. Then the solution was mixed with $1 / 5$ volume of $6 \times$ Loading Buffer $(1 \times$ : $50 \mathrm{mM}$ Tris, $2 \%$ SDS, $0.1 \%$ bromophenol blue, $10 \%$ glycerol) and heated at $90^{\circ} \mathrm{C}$ for $1 \mathrm{~min}$, followed by electrophoresis at $160 \mathrm{~V}$ for around $1 \mathrm{~h}$ on $8 \%$ SDS PAGE in $1 \times$ Running Buffer $(25 \mathrm{mM}$ Tris, 200 $\mathrm{mM}$ glycine, $1 \% \mathrm{mM}$ SDS, $\mathrm{pH}$ 8.3). After stained by InstantBlue (Sigma Aldrich), the gels were imaged by a typical scanner or the Biorad Gel Doc XR+ Gel Documentation System. For Cy-6C3-7SF reacting with RBD in diluted serum, $100 \mathrm{nM}$ DNA and $400 \mathrm{nM}$ protein were used (data shown in Figure 3). Fluorescence imaging (Cy3 channel) was carried out for SDS-PAGE gels without InstantBlue stain, in the Biorad Gel Doc XR+ Gel Documentation System. 


\section{LC-MS/MS analysis of peptide fragmentation for covalent bonding site identification in RBD}

The RBD-6C3-7SF adducts were formed by reacting $1.5 \mu \mathrm{M} 6 \mathrm{C} 3-7 \mathrm{SF}$ with $1 \mu \mathrm{M}$ RBD in $400 \mu \mathrm{L}$ $1 \times \mathrm{PBS}$ containing $2 \mathrm{mM} \mathrm{MgCl} 2$ for $2 \mathrm{~h}$ at $37^{\circ} \mathrm{C}$. The solution was desalted by Amicon- $10 \mathrm{~K}$ ultrafilters using water for 6 times, and then added with $\mathrm{NaOH}$ to reach $100 \mathrm{mM}$ and allowed to react for $0.5 \mathrm{~h}$ at $25{ }^{\circ} \mathrm{C}$ to remove DNA aptamer from RBD-6C3-7SF. The resulting solution was desalted by Amicon$10 \mathrm{~K}$ ultrafilters using water for 6 times and concentrated by Amicon-10K to about $25 \mu \mathrm{L}$, which was further added to $200 \mu \mathrm{L}$ solution containing $2 \mathrm{mM}$ DTT, $8 \mathrm{mM}$ urea, $50 \mathrm{mM}$ Tris- $\mathrm{HCl} \mathrm{pH} 8.3$ and kept for $1 \mathrm{~h}$ at $37{ }^{\circ} \mathrm{C}$ to break cysteine disulfide bonds in RBD. Then, N-ethylmaleimide was added to the solution to $10 \mathrm{mM}$ and a further $1 \mathrm{~h}$ at $37{ }^{\circ} \mathrm{C}$ was allowed to alkylate thiols from both cysteines and SF-modified residues. The solution was subsequently desalted by Amicon-10K ultrafilters using 25 $\mathrm{mM}$ Tris- $\mathrm{HCl} \mathrm{pH} 8.3$ for 6 times and concentrated by Amicon-10K to about $25 \mu \mathrm{L}$. In solution digestion was performed by adding trypsin into the sample at a 1: 50 ratio (w/w, trypsin:protein) and incubating overnight at room temperature. The final solution was acidified and cleaned up using C18 spin columns before LC-MS/MS analysis. Peptides were first separated by UltiMate3000 RSLCnano ultra high performance liquid chromatography (UHPLC) system, and then analyzed by a Thermo Scientific Orbitrap Eclipse Tribrid mass spectrometer equipped with electron transfer dissociation (ETD) functionality at Tsinghua University. Collected MS/MS spectra were searched by Proteome Discoverer 2.4 software, and then were further manually inspected for verification of peptide sequences and modification sites.

As a negative control, $400 \mu \mathrm{L} 1 \mu \mathrm{M}$ RBD was treated using the same protocol as above to confirm no SF-modified residue was detected in the peptide fragmentation signals for the protein itself. For $p$ toluenesulfonyl fluoride reaction, $5 \mathrm{mM}$-toluenesulfonyl fluoride was used instead of $1.5 \mu \mathrm{M} 6 \mathrm{C} 3$ $7 \mathrm{SF}$, and all the other steps were the same as above.

\section{RBD-ACE inhibition activity assay using ELISA}

Coating Step: In the high-bind 96-well plates, $2.5 \mathrm{ng} / \mu \mathrm{L} \mathrm{RBD}$ or its variant in $100 \mu \mathrm{L}$ Coating Buffer (15 mM Na $2 \mathrm{CO}_{3}, 35 \mathrm{mM} \mathrm{NaHCO} 3, \mathrm{pH}$ 9.6) was added to each well except for the blank wells (no RBD). The plates were covered by tape and kept for $2 \mathrm{~h}$ at $37^{\circ} \mathrm{C}$.

Blocking Step: After washing each well by $300 \mu \mathrm{L}$ Washing Buffer (1× PBS, pH 7.4, 0.05\% 
Tween-20) for three times, the plates were blocked by adding $300 \mu \mathrm{L}$ Blocking Buffer (2\% BSA, 1× PBS, pH 7.4) to each well. The plates were covered by tape and kept for $1 \mathrm{~h}$ at $37^{\circ} \mathrm{C}$.

Reacting Step: After washing each well by $300 \mu \mathrm{L}$ Reacting Buffer $(1 \times \mathrm{PBS}, 2 \mathrm{mM} \mathrm{MgCl}$, pH 7.4) for three times, aptamer samples in $100 \mu \mathrm{L}$ Reacting Buffer were added to each well. Negative and positive controls were $100 \mu \mathrm{L}$ Reacting Buffer and 500 nM ACE2 in $100 \mu \mathrm{L}$ Reacting Buffer, respectively. The plates were covered by tape and kept for $2 \mathrm{~h}$ at $37^{\circ} \mathrm{C}$.

Binding Step: After washing each well by $300 \mu \mathrm{L}$ Washing Buffer for three times, $0.12 \mathrm{ng} / \mu \mathrm{L}$ biotinylated ACE2 in $100 \mu \mathrm{L}$ Washing Buffer was added to each well. The plates were covered by tape and kept for $0.5 \mathrm{~h}$ at $37^{\circ} \mathrm{C}$.

Labeling Step: After washing each well by $300 \mu \mathrm{L}$ Washing Buffer for three times, $0.1 \mathrm{ng} / \mu \mathrm{L}$ Streptavidin-HRP in $100 \mu \mathrm{L}$ Washing Buffer was added to each well. The plates were covered by tape and kept for $0.5 \mathrm{~h}$ at $37^{\circ} \mathrm{C}$.

Testing Step: After washing each well by $300 \mu \mathrm{L}$ Washing Buffer for three times, $100 \mu \mathrm{L}$ substrate solution from the kit (ELISA reagent set, Cat\# EBS-001, Acro Biosystems) was added to each well. Blue color generation was observed from the HRP-active wells. After about 20 min of enzymatic reaction, $50 \mu \mathrm{L}$ stop solution from the kit was added to each well and the blue color turned yellow. The plates were read at $450 \mathrm{~nm}$ using a UV/Vis microplate spectrophotometer.

For all the above tests, each sample was repeated at least twice in one set of experiment, and two such sets were carried out.

\section{Author Contributions}

Zichen Qin: Synthesis of SuFEx-aptamers, PAGE and SDS-PAGE analyses, ELSIA, manuscript preparation; Yiying Zhu: LC-MS/MS measurement and data analyses, manuscript preparation; Yu Xiang: Design of the study, synthesis of SuFEx-aptamers, PAGE and SDS-PAGE analyses, ELSIA, manuscript preparation. 


\section{Acknowledgement}

This work is supported by the National Natural Science Foundation of China (Nos. 21621003 and 22074076). We thank Ms. Mingyun Wang from Boston College for the help in manuscript proofreading.

\section{References}

1. Lan, J.; Ge, J.; Yu, J.; Shan, S.; Zhou, H.; Fan, S.; Zhang, Q.; Shi, X.; Wang, Q.; Zhang, L.; Wang, $\mathrm{X}$., Structure of the SARS-CoV-2 spike receptor-binding domain bound to the ACE2 receptor. Nature 2020, 581, 215-220.

2. Shang, J.; Ye, G.; Shi, K.; Wan, Y. S.; Luo, C. M.; Aihara, H.; Geng, Q. B.; Auerbach, A.; Li, F., Structural basis of receptor recognition by SARS-CoV-2. Nature 2020, 581, 221-224.

3. Guo, Y.; Huang, L.; Zhang, G.; Yao, Y.; Zhou, H.; Shen, S.; Shen, B.; Li, B.; Li, X.; Zhang, Q.; Chen, M.; Chen, D.; Wu, J.; Fu, D.; Zeng, X.; Feng, M.; Pi, C.; Wang, Y.; Zhou, X.; Lu, M.; Li, Y.; Fang, Y.; Lu, Y. Y.; Hu, X.; Wang, S.; Zhang, W.; Gao, G.; Adrian, F.; Wang, Q.; Yu, F.; Peng, Y.; Gabibov, A. G.; Min, J.; Wang, Y.; Huang, H.; Stepanov, A.; Zhang, W.; Cai, Y.; Liu, J.; Yuan, Z.; Zhang, C.; Lou, Z.; Deng, F.; Zhang, H.; Shan, C.; Schweizer, L.; Sun, K.; Rao, Z., A SARSCoV-2 neutralizing antibody with extensive spike binding coverage and modified for optimal therapeutic outcomes. Nat. Commun. 2021, 12, 2623.

4. Jones, B. E.; Brown-Augsburger, P. L.; Corbett, K. S.; Westendorf, K.; Davies, J.; Cujec, T. P.; Wiethoff, C. M.; Blackbourne, J. L.; Heinz, B. A.; Foster, D.; Higgs, R. E.; Balasubramaniam, D.; Wang, L.; Zhang, Y.; Yang, E. S.; Bidshahri, R.; Kraft, L.; Hwang, Y.; Zentelis, S.; Jepson, K. R.; Goya, R.; Smith, M. A.; Collins, D. W.; Hinshaw, S. J.; Tycho, S. A.; Pellacani, D.; Xiang, P.; Muthuraman, K.; Sobhanifar, S.; Piper, M. H.; Triana, F. J.; Hendle, J.; Pustilnik, A.; Adams, A. C.; Berens, S. J.; Baric, R. S.; Martinez, D. R.; Cross, R. W.; Geisbert, T. W.; Borisevich, V.; Abiona, O.; Belli, H. M.; de Vries, M.; Mohamed, A.; Dittmann, M.; Samanovic, M. I.; Mulligan, M. J.; Goldsmith, J. A.; Hsieh, C. L.; Johnson, N. V.; Wrapp, D.; McLellan, J. S.; Barnhart, B. C.; Graham, B. S.; Mascola, J. R.; Hansen, C. L.; Falconer, E., The neutralizing antibody, LY-CoV555, protects against SARS-CoV-2 infection in nonhuman primates. Sci. Transl. Med. 2021, 13, eabf1906.

5. Bojadzic, D.; Alcazar, O.; Chen, J.; Chuang, S. T.; Condor Capcha, J. M.; Shehadeh, L. A.; Buchwald, P., Small-molecule inhibitors of the coronavirus spike: ACE2 protein-protein interaction as blockers of viral attachment and entry for SARS-CoV-2. ACS Infect. Dis. 2021, 7, 1519-1534.

6. Toelzer, C.; Gupta, K.; Yadav, S. K. N.; Borucu, U.; Davidson, A. D.; Williamson, M. K.; Shoemark, D. K.; Garzoni, F.; Staufer, O.; Milligan, R.; Capin, J.; Mulholland, A. J.; Spatz, J.; Fitzgerald, D.; Berger, I.; Schaffitzel, C., Free fatty acid binding pocket in the locked structure of SARS-CoV-2 spike protein. Science 2020, 370, 725-730.

7. Schutz, D.; Ruiz-Blanco, Y. B.; Munch, J.; Kirchhoff, F.; Sanchez-Garcia, E.; Muller, J. A., 
Peptide and peptide-based inhibitors of SARS-CoV-2 entry. Adv. Drug Deliv. Rev. 2020, 167, 4765.

8. Larue, R. C.; Xing, E. M.; Kenney, A. D.; Zhang, Y. X.; Tuazon, J. A.; Li, J. R.; Yount, J. S.; Li, P. K.; Sharma, A., Rationally designed ACE2-derived peptides inhibit SARS-CoV-2. Bioconjug. Chem. 2021, 32, 215-223.

9. Sun, M.; Liu, S.; Wei, X.; Wan, S.; Huang, M.; Song, T.; Lu, Y.; Weng, X.; Lin, Z.; Chen, H.; Song, Y.; Yang, C., Aptamer blocking strategy inhibits SARS-CoV-2 virus infection. Angew. Chem. Int. Ed. 2021, 60, 10266-10272.

10. Liu, X.; Wang, Y. L.; Wu, J.; Qi, J.; Zeng, Z.; Wan, Q.; Chen, Z.; Manandhar, P.; Cavener, V. S.; Boyle, N. R.; Fu, X.; Salazar, E.; Kuchipudi, S. V.; Kapur, V.; Zhang, X.; Umetani, M.; Sen, M.; Willson, R. C.; Chen, S. H.; Zu, Y., Neutralizing aptamers block S/RBD-ACE2 interactions and prevent host cell infection. Angew. Chem. Int. Ed. 2021, 60, 10273-10278.

11. Singh, J.; Petter, R. C.; Baillie, T. A.; Whitty, A., The resurgence of covalent drugs. Nat. Rev. Drug Discovery 2011, 10, 307-317.

12. Lagoutte, R.; Patouret, R.; Winssinger, N., Covalent inhibitors: An opportunity for rational target selectivity. Curr. Opin. Chem. Biol. 2017, 39, 54-63.

13. Lonsdale, R.; Ward, R. A., Structure-based design of targeted covalent inhibitors. Chem. Soc. Rev. 2018, 47, 3816-3830.

14. Zhang, T. H.; Hatcher, J. M.; Teng, M. X.; Gray, N. S.; Kostic, M., Recent advances in selective and irreversible covalent ligand development and validation. Cell Chem. Biol. 2019, 26, 14861500 .

15. Mukherjee, H.; Grimster, N. P., Beyond cysteine: Recent developments in the area of targeted covalent inhibition. Curr. Opin. Chem. Biol. 2018, 44, 30-38.

16. Moore, A. R.; Rosenberg, S. C.; McCormick, F.; Malek, S., Ras-targeted therapies: Is the undruggable drugged? Nat. Rev. Drug Discovery 2020, 19, 533-552.

17. Abdeldayem, A.; Raouf, Y. S.; Constantinescu, S. N.; Moriggl, R.; Gunning, P. T., Advances in covalent kinase inhibitors. Chem. Soc. Rev. 2020, 49, 2617-2687.

18. Dai, W.; Zhang, B.; Jiang, X. M.; Su, H.; Li, J.; Zhao, Y.; Xie, X.; Jin, Z.; Peng, J.; Liu, F.; Li, C.; Li, Y.; Bai, F.; Wang, H.; Cheng, X.; Cen, X.; Hu, S.; Yang, X.; Wang, J.; Liu, X.; Xiao, G.; Jiang, H.; Rao, Z.; Zhang, L. K.; Xu, Y.; Yang, H.; Liu, H., Structure-based design of antiviral drug candidates targeting the SARS-CoV-2 main protease. Science 2020, 368, 1331-1335.

19. Karges, J.; Kalaj, M.; Gembicky, M.; Cohen, S. M., Re-I tricarbonyl complexes as coordinate covalent inhibitors for the SARS-CoV-2 main cysteine protease. Angew. Chem. Int. Ed. 2021, 60, 10716-10723.

20. Chaikuad, A.; Koch, P.; Laufer, S. A.; Knapp, S., The cysteinome of protein kinases as a target in drug development. Angew. Chem. Int. Ed. 2018, 57, 4372-4385.

21. Pettinger, J.; Jones, K.; Cheeseman, M. D., Lysine-targeting covalent inhibitors. Angew. Chem. Int. Ed. 2017, 56, 15200-15209.

22. Ueda, T.; Tamura, T.; Kawano, M.; Shiono, K.; Hobor, F.; Wilson, A. J.; Hamachi, I., Enhanced suppression of a protein-protein interaction in cells using small-molecule covalent inhibitors based on an n-acyl-n-alkyl sulfonamide warhead. J. Am. Chem. Soc. 2021, 143, 4766-4774.

23. Gambini, L.; Baggio, C.; Udompholkul, P.; Jossart, J.; Salem, A. F.; Perry, J. J. P.; Pellecchia, M., Covalent inhibitors of protein-protein interactions targeting lysine, tyrosine, or histidine residues. J. Med. Chem. 2019, 62, 5616-5627. 
24. Gambini, L.; Udompholkul, P.; Baggio, C.; Muralidharan, A.; Kenjic, N.; Assar, Z.; Perry, J. J. P.; Pellecchia, M., Design, synthesis, and structural characterization of lysine covalent BH3 peptides targeting Mcl-1. J. Med. Chem. 2021, 64, 4903-4912.

25. Li, Q. K.; Chen, Q.; Klauser, P. C.; Li, M. Y.; Zheng, F.; Wang, N. X.; Li, X. Y.; Zhang, Q. B.; Fu, X. M.; Wang, Q.; Xu, Y.; Wang, L., Developing covalent protein drugs via proximity-enabled reactive therapeutics. Cell 2020, 182, 85-97.

26. Berdan, V. Y.; Klauser, P. C.; Wang, L., Covalent peptides and proteins for therapeutics. Bioorg. Med. Chem. 2021, 29, 115896.

27. Dong, J. J.; Krasnova, L.; Finn, M. G.; Sharpless, K. B., Sulfur(VI) fluoride exchange (SuFEx): Another good reaction for click chemistry. Angew. Chem. Int. Ed. 2014, 53, 9430-9448.

28. Narayanan, A.; Jones, L. H., Sulfonyl fluorides as privileged warheads in chemical biology. Chem. Sci. 2015, 6, 2650-2659.

29. Martin-Gago, P.; Olsen, C. A., Arylfluorosulfate-based electrophiles for covalent protein labeling: A new addition to the arsenal. Angew. Chem. Int. Ed. 2019, 58, 957-966.

30. Brighty, G. J.; Botham, R. C.; Li, S. H.; Nelson, L.; Mortenson, D. E.; Li, G. C.; Morisseau, C.; Wang, H.; Hammock, B. D.; Sharpless, K. B.; Kelly, J. W., Using sulfuramidimidoyl fluorides that undergo sulfur(vi) fluoride exchange for inverse drug discovery. Nat. Chem. 2020, 12, 906-913.

31. Maurais, A. J.; Weerapana, E., Reactive-cysteine profiling for drug discovery. Curr. Opin. Chem. Biol. 2019, 50, 29-36.

32. Tan, W. H.; Donovan, M. J.; Jiang, J. H., Aptamers from cell-based selection for bioanalytical applications. Chem. Rev. 2013, 113, 2842-2862.

33. Zhou, J. H.; Rossi, J., Aptamers as targeted therapeutics: Current potential and challenges. Nat. Rev. Drug Discovery 2017, 16, 181-202.

34. Tabuchi, Y.; Yang, J.; Taki, M., Inhibition of thrombin activity by a covalent-binding aptamer and reversal by the complementary strand antidote. Chem. Commun. 2021, 57, 2483-2486.

35. Tivon, Y.; Falcone, G.; Deiters, A., Protein labeling and crosslinking by covalent aptamers. Angew. Chem. Int. Ed. 2021, 60, 15899-15904.

36. Xiao, L.; Gu, C.; Xiang, Y., Orthogonal activation of RNA-cleaving dnazymes in live cells by reactive oxygen species. Angew. Chem. Int. Ed. 2019, 58, 14167-14172.

37. Gu, C. M.; Xiao, L.; Shang, J. C.; Xu, X.; He, L.; Xiang, Y., Chemical synthesis of stimuliresponsive guide RNA for conditional control of CRISPR-Cas9 gene editing. Chem. Sci. 2021, 10.1039/D1SC01194D.

38. Wang, X. Y.; Feng, M. L.; Xiao, L.; Tong, A. J.; Xiang, Y., Postsynthetic modification of DNA phosphodiester backbone for photocaged DNAzyme. ACS Chem. Biol. 2016, 11, 444-451.

39. Xiao, L.; Zhou, Z. J.; Feng, M. L.; Tong, A. J.; Xiang, Y., Cationic peptide conjugation enhances the activity of peroxidase-mimicking dnazymes. Bioconjug. Chem. 2016, 27, 621-627.

40. Hou, Y. J.; Chiba, S.; Halfmann, P.; Ehre, C.; Kuroda, M.; Dinnon, K. H., 3rd; Leist, S. R.; Schafer, A.; Nakajima, N.; Takahashi, K.; Lee, R. E.; Mascenik, T. M.; Graham, R.; Edwards, C. E.; Tse, L. V.; Okuda, K.; Markmann, A. J.; Bartelt, L.; de Silva, A.; Margolis, D. M.; Boucher, R. C.; Randell, S. H.; Suzuki, T.; Gralinski, L. E.; Kawaoka, Y.; Baric, R. S., SARS-CoV-2 D614G variant exhibits efficient replication ex vivo and transmission in vivo. Science 2020, 370, 1464 1468.

41. Gobeil, S. M.; Janowska, K.; McDowell, S.; Mansouri, K.; Parks, R.; Stalls, V.; Kopp, M. F.; Manne, K.; Li, D.; Wiehe, K.; Saunders, K. O.; Edwards, R. J.; Korber, B.; Haynes, B. F.; 
Henderson, R.; Acharya, P., Effect of natural mutations of SARS-CoV-2 on spike structure, conformation, and antigenicity. Science 2021, 10.1126/science.abi6226.

42. Carpino, L. A.; Shroff, H.; Triolo, S. A.; Mansour, E. M. E.; Wenschuh, H.; Albericio, F., The 2,2,4,6,7-pentamethyldihydrobenzofuran-5-sulfonyl group (pbf) as arginine side-chain protectant. Tetrahedron Lett. 1993, 34, 7829-7832.

43. Isidro, A.; Latassa, D.; Giraud, M.; Alvarez, M.; Albericio, F., 1,2-dimethylindole-3-sulfonyl (mis) as protecting group for the side chain of arginine. Org. Biomol. Chem. 2009, 7, 2565-2569.

44. Antonysamy, S.; Bonday, Z.; Campbell, R. M.; Doyle, B.; Druzina, Z.; Gheyi, T.; Han, B.; Jungheim, L. N.; Qian, Y. W.; Rauch, C.; Russell, M.; Sauder, J. M.; Wasserman, S. R.; Weichert, K.; Willard, F. S.; Zhang, A. P.; Emtage, S., Crystal structure of the human PRMT5:MEP50 complex. Proc. Natl. Acad. Sci. U. S. A. 2012, 109, 17960-17965.

45. Fu, W. Y.; Chen, Y. J. A.; Wang, K. D.; Hettinghouse, A.; Hu, W. H.; Wang, J. Q.; Lei, Z. N.; Chen, Z. S.; Stapleford, K. A.; Liu, C. J., Repurposing FDA-approved drugs for SARS-CoV-2 through an ELISA-based screening for the inhibition of RBD/ACE2 interaction. Protein Cell 2021, 12, 586-591.

46. Crooke, S. T.; Baker, B. F.; Crooke, R. M.; Liang, X. H., Antisense technology: An overview and prospectus. Nat. Rev. Drug Discovery 2021, 20, 427-453.

47. Adams, D.; Gonzalez-Duarte, A.; O'Riordan, W. D.; Yang, C. C.; Ueda, M.; Kristen, A. V.; Tournev, I.; Schmidt, H. H.; Coelho, T.; Berk, J. L.; Lin, K. P.; Vita, G.; Attarian, S.; PlanteBordeneuve, V.; Mezei, M. M.; Campistol, J. M.; Buades, J.; Brannagan, T. H.; Kim, B. J.; Oh, J.; Parman, Y.; Sekijima, Y.; Hawkins, P. N.; Solomon, S. D.; Polydefkis, M.; Dyck, P. J.; Gandhi, P. J.; Goyal, S.; Chen, J.; Strahs, A. L.; Nochur, S. V.; Sweetser, M. T.; Garg, P. P.; Vaishnaw, A. K.; Gollob, J. A.; Suhr, O. B., Patisiran, an rnai therapeutic, for hereditary transthyretin amyloidosis. N. Engl. J. Med. 2018, 379, 11-21. 